\title{
Heating and dehumidification in production greenhouses at northern latitudes: energy use
}

F. Kempkes 1 ,a, H.F. de Zwart ${ }^{1}$, P. Munoz ${ }^{2}$, J.I. Montero², F.J. Baptista ${ }^{3}$, F. Giuffrida ${ }^{4}$, C. Gilli5, A. Stepowska ${ }^{6}$ and C. Stanghellini ${ }^{1}$

1Wageningen UR Greenhouse Horticulture, Wageningen, The Netherlands; 2 Irta, Cabrils Barcelona, Spain; 3Departamento de Engenharia Rural, Escola de Ciências e Tecnologia, Universidade de Évora e ICAAM, Évora, Portugal; ${ }^{4}$ Dipartimento di Agricoltura, Alimentazione e Ambiente, Università di Catania, Catania, Italy; ${ }^{5}$ Agroscope, Conthey, Switzerland; ${ }^{6}$ Research Institute of Horticulture, Skierniewice, Poland.

\begin{abstract}
The majority of greenhouses in northern latitudes are heated, in the winter mainly for temperature control and year round to control humidity. Heating is accepted by most organic regulations in different countries; if heating efficiently and the energy source is predominantly renewable energy, heating fits well into the concept of organic production, since it is aligned with the idea of achieving maximum potential with available resources. It is a fact that energy use for humidity control is more important than for heating. Indeed, the improved thermal performance (insulation) of high-tech greenhouses has decreased heating requirements while decreasing the discharge pathways of vapour at the same time. The need to control humidity is especially important in organic greenhouses, given the limited options to fight fungal diseases once they develop. Excess vapour can be discharged in three ways: through exchange with dry outside air (ventilation), through condensation on a cold surface and through hygroscopic adsorption. Ventilation can be uncontrolled (natural) or controlled (forced), and in the latter case can be controlled by a heat exchanger, recovering sensible heat in the ventilated air. Even then, however, the latent heat contained in the vapour (the energy used for evaporation) will be lost. In those cases where the greenhouse is dehumidified by withdrawing internal moisture, the loss of latent heat via ventilation is prevented and condensation on an internal surface recovers the latent heat. Obviously, it costs energy to cool the condensation surface and/or regenerate the hygroscopic salt. Experiments with these systems have been performed during the last years. Some growers have installed these types of systems and they have been monitored for their effect on moisture control and energy saving. The results of these experiments and model calculations to compare them are presented. In case dehumidification systems are well controlled they can save significant amounts of the energy and with an increase of technology level the saving can be improved. There is no generally best possible solution for dehumidification. The optimum system and its operation is dependent on desired temperature and humidity level in the greenhouse.
\end{abstract}

Keywords: energy efficiency, sustainable production, humidity, energy saving

\section{INTRODUCTION}

The Dutch horticultural sector has formulated goals in the energy research program "Kas als Energiebron". These goals state that the horticulture sector will not emit more than 6.2 megatons of $\mathrm{CO}_{2}$ in 2020, including $\mathrm{CO}_{2}$ emissions from the supply of electricity. In addition, energy savings of 11 PJ will have to be realized by 2020 . The Dutch horticultural sector has even more ambitions: in 2020, newly built greenhouses must be economically profitable and operating climate neutral without the use of fossil energy. For existing greenhouses concepts, techniques are being developed for economically profitable

aE-mail: Frank.Kempkes@wur.nl 